This item was submitted to Loughborough's Research Repository by the author.

Items in Figshare are protected by copyright, with all rights reserved, unless otherwise indicated.

\title{
'Stealth' nanoparticles evade neural immune cells but also evade major brain cell populations: Implications for PEG-based neurotherapeutics
}

PLEASE CITE THE PUBLISHED VERSION

http://dx.doi.org/10.1016/j.jconrel.2016.01.013

\section{PUBLISHER}

(C) Elsevier

VERSION

AM (Accepted Manuscript)

\section{PUBLISHER STATEMENT}

This work is made available according to the conditions of the Creative Commons Attribution-NonCommercialNoDerivatives 4.0 International (CC BY-NC-ND 4.0) licence. Full details of this licence are available at: https://creativecommons.org/licenses/by-nc-nd/4.0/

\section{LICENCE}

CC BY-NC-ND 4.0

\section{REPOSITORY RECORD}

Jenkins, Stuart I., Daniel Weinberg, Arwa F. Al-Shakli, Alinda R. Fernandes, Humphrey H. Yiu, Neil D. Telling, Paul Roach, and Divya M. Chari. 2019. "'stealth' Nanoparticles Evade Neural Immune Cells but Also Evade Major Brain Cell Populations: Implications for Peg-based Neurotherapeutics”. figshare. https://hdl.handle.net/2134/25860. 

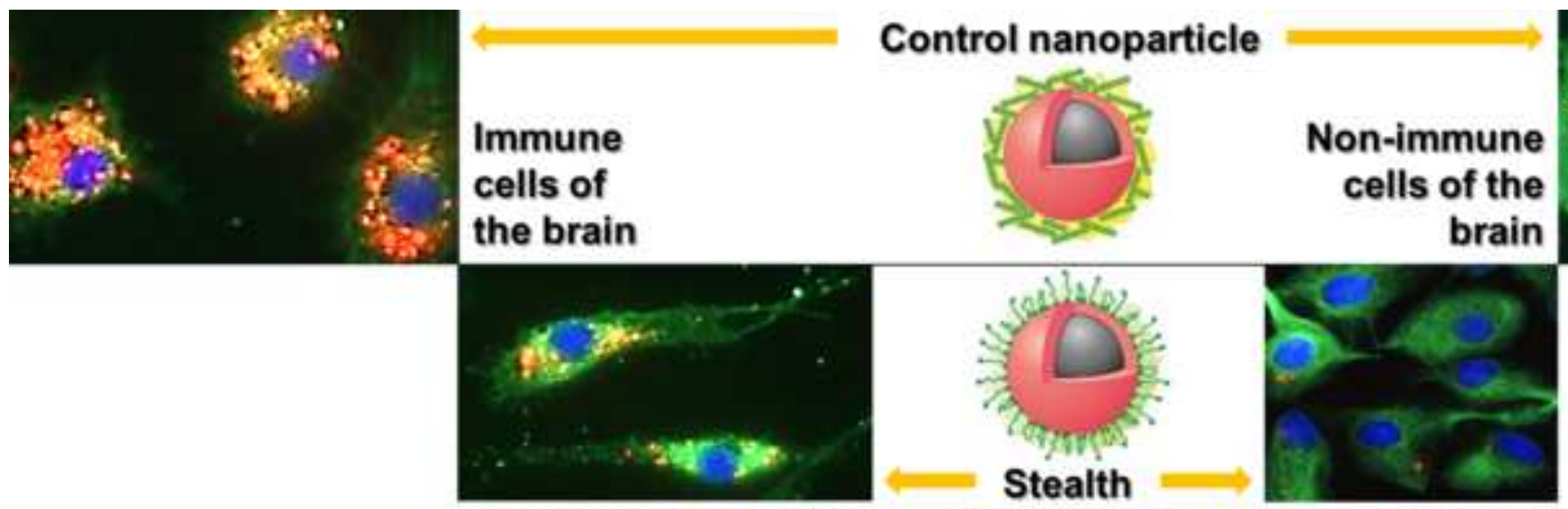

Reduction in uptake

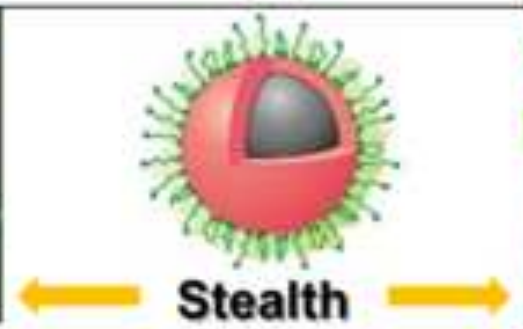
nanoparticle

Reduction in uptake
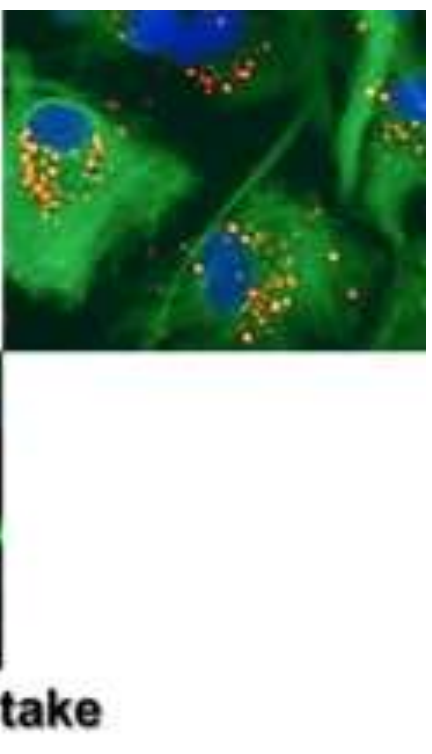
'Stealth' nanoparticles evade neural immune cells but also evade all major brain cell populations:

\section{Implications for PEG-based neurotherapeutics}

Stuart I Jenkins ${ }^{\mathrm{a} \ddagger}$, Daniel Weinberg ${ }^{\mathrm{a} \ddagger}$, Arwa F al-Shakli ${ }^{\mathrm{a}}$, Alinda R Fernandes ${ }^{\mathrm{a}}$, Humphrey H P Yiu ${ }^{\mathrm{b}}$, Neil D Telling ${ }^{\mathrm{a}}$, Paul Roach ${ }^{\mathrm{a}}$, Divya M Chari ${ }^{\mathrm{a} *}$

†These authors contributed equally to the experiments and manuscript.

${ }^{a}$ Institute for Science and Technology in Medicine, Keele University, Keele, Staffordshire, ST5 5BG, United Kingdom

s.i.jenkins@keele.ac.uk

weinberg@hotmail.co.uk

a.f.j.al-shakli@keele.ac.uk

a.fernandes@keele.ac.uk

n.d.telling@keele.ac.uk

p.roach@keele.ac.uk

${ }^{\mathrm{b}}$ Chemical Engineering, School of Engineering and Physical Sciences, Heriot-Watt University, Edinburgh EH14 4AS, United Kingdom

H.H.Yiu@hw.ac.uk

Corresponding Author: *Prof. Divya M. Chari, Institute for Science and Technology in Medicine, School of Medicine, David Weatherall Building, Keele University, Staffordshire, ST5 5BG, UK.

d.chari@keele.ac.uk

Tel: +44 1782 733314; Fax: +44 1782734634 . 


\section{Abstract}

Surface engineering to control cell behaviour is of high interest across the chemical engineering, drug delivery and biomaterials communities. Defined chemical strategies are necessary to tailor nanoscale protein interactions/adsorption, enabling control of cell behaviours for development of novel therapeutic strategies. Nanoparticle-based therapies benefit from such strategies but particle targeting to sites of neurological injury remains challenging due to circulatory immune clearance. As a strategy to overcome this barrier, the use of stealth coatings can reduce immune clearance and prolong circulatory times, thereby enhancing therapeutic capacity. Polyethylene glycol (PEG) is the most widely-used stealth coating and facilitates particle accumulation in the brain. However, once within the brain, the handling of PEGylated particles by the resident immune cells of the brain itself (the 'microglia') is unknown. This is a critical question as it is well established that microglia avidly sequester nanoparticles, limiting their bioavailability and posing a major translational barrier. If PEGylation can be proved to promote evasion of microglia, then this information will be of high value in developing tailored nanoparticle-based therapies for neurological applications. Here, we have conducted the first comparative study of uptake of PEGylated particles by all the major (immune and non-immune) brain cell types. We prove for the first time that PEGylated nanoparticles evade all the major brain cell populations - a phenomenon which will enhance extracellular bioavailability. We demonstrate changes in protein coronas around these particles within biological media, and discuss how surface chemistry presentation may affect this process and subsequent cellular interactions.

Keywords: astrocytes; microglia; oligodendrocyte precursor cells; neural stem cells; targeting; corona

Chemical compounds: ethylene glycol (PubChem CID: 174); dextran (PubChem CID: 4125253); magnetite (PubChem CID: 9816051) 


\section{Introduction}

A major emergent area of nanotechnology research is the development of diverse nanoparticle platforms for biomedical applications, including the treatment of neurological disease/injury [1,2]. Nanoparticle delivery to the central nervous system (CNS) represents a critical biological challenge in this context [3]. Direct nanoparticle delivery to the CNS via intracerebral, intraventricular and intrathecal routes can produce high doses near target sites, but involves risk of clinical complications including embolism and haemorrhage [4]. However, for systemically delivered nanoparticles to reach sites of neurological injury, major biological barriers must be overcome (shown schematically in Figure 1). The first is particle clearance by immune cells in the bloodstream and tissue systems/organs such as the liver, spleen and lungs (termed the mononuclear phagocyte system, MPS; formerly the reticuloendothelial system, RES) [5]. This necessitates use of high particle concentrations (with risks of associated toxicity) to achieve therapeutic benefit [6]. Second, neural tissue is partitioned from the bloodstream by the blood-brain barrier (BBB), which has its cellular basis in tight junctions between brain capillary endothelial cells, sealing off the paracellular pathway for biomolecule transport [7]. Transcellular transport across the BBB is also tightly regulated, utilizing a limited number of carrier proteins/receptors to transport essential biomolecules (e.g. insulin, leptin) into and out of the CNS [8]. This highly selective BBB restricts access of most therapeutic agents to the brain parenchyma $[3,9]$. Strategies to overcome these barriers have been the focus of intensive biological investigation in recent decades.

Once introduced into physiological media (e.g. blood, following systemic delivery), nanoparticles rapidly acquire a biomolecule 'corona' [10,11]. Cells interact with this particle-corona composite which may display altered physicochemical properties compared to the bare particle, influencing particle fate [12]. For example, opsonin adsorption increases particle clearance by MPS cells; modification of particle surface chemistry can overcome this limitation by reducing non-specific adsorption of biomolecules such as serum proteins, including opsonins, limiting MPS clearance and prolonging blood circulation time for nanoparticles. This chemical approach represents a key strategy to overcome the above barriers, and such 'stealth' coatings are widely used currently to facilitate drug/gene delivery $[6,13,14]$. In particular, polyethylene glycol (PEG) is a widely used polymer used to impart stealth properties. PEGylated materials 
evade the MPS, enhancing bioavailability, and possess the ability to cross the BBB, for which the exact mechanism is unknown but could include transcytosis or receptor-mediated endocytosis [15]. PEG-coated nanoparticles accumulate in brain tissue more effectively than non-PEG-coated nanoparticles, and those coated with high density PEG also display greater diffusion through brain parenchyma $[4,16]$. Of high relevance for clinical applications, PEG-coated nanoparticle accumulation is enhanced in pathological foci including gliosarcoma and Multiple Sclerosis models [17,18], possibly due to inflammation-induced BBB hyperpermeability - similar to enhanced nanoparticle permeability/retention (EPR effect) in brain tumors [19].

Such findings are encouraging but it should be noted here that a third, and currently poorly understood biological barrier exists, namely, the immune component of the CNS itself, consisting of cells called microglia. These highly motile cells constantly monitor their microenvironment and demonstrate high endocytotic/phagocytic activity [20,21] exhibiting dramatically more rapid/extensive nanoparticle uptake than all other neural subtypes, in vitro [22] and in vivo [23]. This constitutes a significant 'extracellular barrier' to particle uptake by other neural cell types by 'out-competing' them [22]. This differential uptake and competitive sequestration has profound implications for clinical nanoparticle therapies for neural applications. Despite this, two major knowledge gaps exist. First, it is currently unknown if the PEGylation strategy specifically limits microglial nanoparticle clearance. Second, there are no comparative data regarding the handling of such nanoparticles by the other major (non-immune) neural cell types - an issue of high relevance given the complex, multicellular environment of the brain where cells with distinct endocytotic profiles (and nanoparticle uptake features) co-exist. 


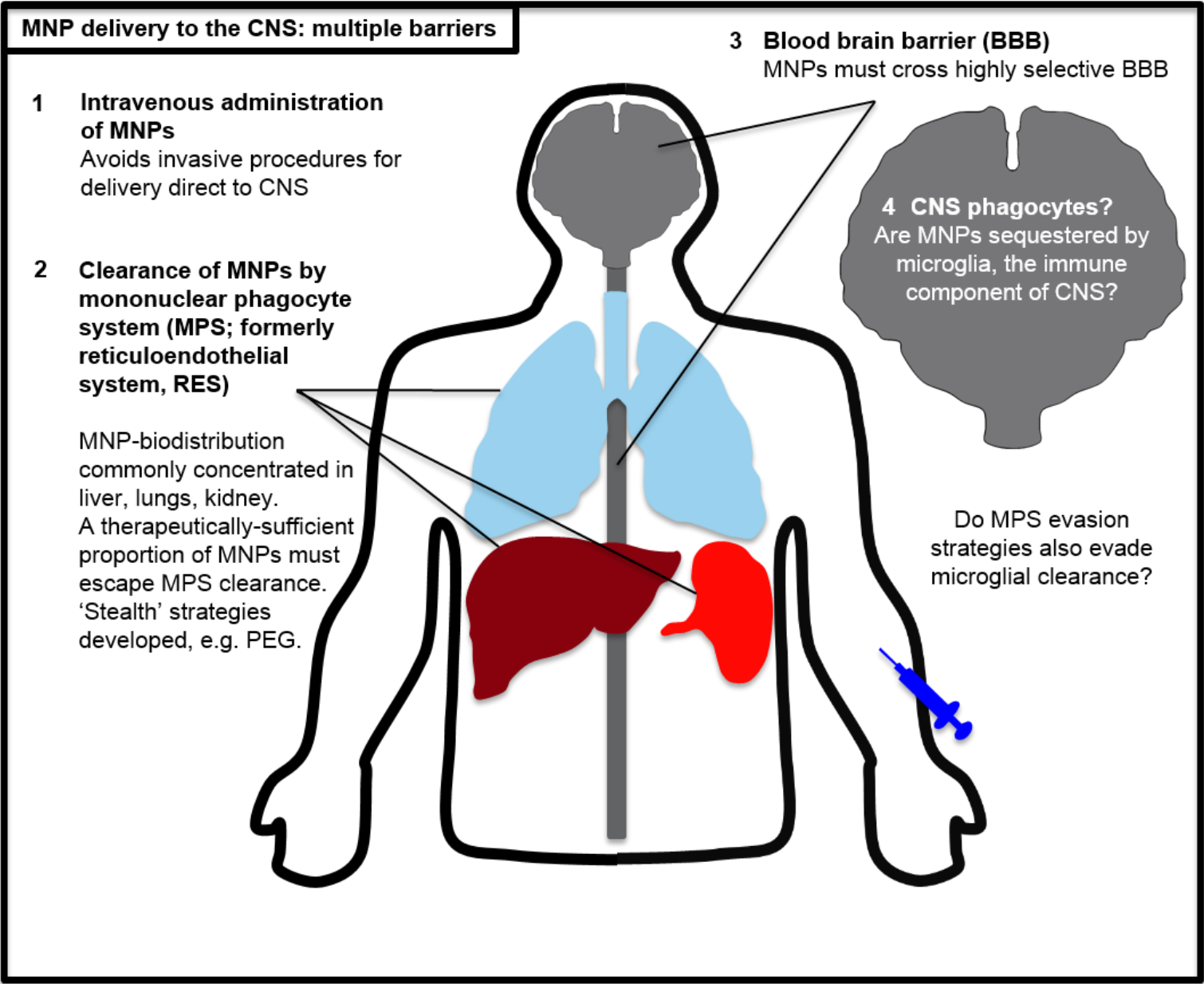

Figure 1. Schematic diagram illustrating the major barriers that must be overcome by CNS-targeted nanoparticles following systemic delivery.

We have addressed this issue by studying the uptake of PEGylated magnetic nanoparticles (MNPs) by five major cell types of the brain viz. microglia, astrocytes (the major homeostatic regulators of the CNS), oligodendrocyte precursor cells (OPCs; which generate oligodendrocytes and ultimately myelin, the insulating sheath around nerve fibres), neurons (the transmitters of electrical signals) and neural stem cells (NSCs; the major stem/precursor cells of the CNS). MNPs were selected for these experiments as they offer combined capacity for biomolecule delivery and nanoparticle imaging in sites of pathology for neurological applications [24,25]. The specific study aims were to: (i) assess if PEGylation reduces particle clearance by microglial cells; (ii) conduct a pan-cellular assessment of uptake of PEGylated nanoparticles in the major brain cell types; (iii) identify protein corona features that may contribute to differing particle uptake profiles. 


\section{Materials and Methods}

The care and use of animals was in accordance with the Animals (Scientific Procedures) Act of 1986 (United Kingdom) with approval by the local ethics committee.

\subsection{Materials}

DAPI (4',6-diamidino-2-phenylindole) mounting medium was from Vector Laboratories (Peterborough, UK). Lectin and monoclonal anti-biotin-FITC (fluorescein isothiocyanate) secondary antibody (clone BN-34) were from Sigma-Aldrich (Poole, UK). All other secondary antibodies were from Jackson ImmunoResearch Laboratories Inc. (West Grove, PA, USA). Both carboxymethyl dextran-coated magnetic nanoparticles (nano-screenMAG-CMX; termed CMX-MNPs) and polyethylene glycol-coated magnetic nanoparticles (nano-screenMAG-PEG/P; termed PEGMNPs) were supplied by Chemicell as aqueous suspensions. They were synthesized by the same manufacturer, having magnetite cores with a lipophilic dye (BODIPY) layer, overcoated with either carboxymethyl dextran (CMX-MNP) or 2 kDa diphosphate PEG (PEG-MNP).

\subsection{Particle coating characterization, FTIR}

For MNP analysis in water, FTIR was performed using a Perkin Elmer Spectrum 100 spectrometer (MA, USA) fitted with an attenuated total reflection sampling unit (32 scans; $650-4000 \mathrm{~cm}^{-1}$; resolution of $\left.4 \mathrm{~cm}^{-1}\right)$.

\subsection{Dynamic light scattering and zeta potential measurements}

The hydrodynamic diameter and zeta-potential of CMX- and PEG-MNPs in cellular media (without cells) were determined using a Zetasizer Nano ZS (Malvern, UK). All media contain carbonate buffer to maintain a pH of $\sim 7.4$ while incubated $\left(37{ }^{\circ} \mathrm{C}, 5 \% \mathrm{CO}_{2} / 95 \%\right.$ humidified air). As $\mathrm{pH}$ can influence particle-media interactions, cell culture conditions were replicated: media were incubated for $24 \mathrm{~h}$ prior to particle addition $\left(50 \mu \mathrm{g} \mathrm{mL}^{-1}\right)$ with the $5 \% \mathrm{CO}_{2}$ headspace being sealed between removal and measurement.

\subsection{Corona characterization, FTIR}

For coronal analyses, MNPs were incubated in media $\left(3 \mathrm{~h} ; 20 \mu \mathrm{g} \mathrm{mL}^{-1}\right)$, magnetically separated, washed and air dried onto aluminum discs. FTIR data was collected on a Bruker Alpha system fitted with a diffuse 
reflection infrared Fourier transform spectroscopy (DRIFT) accessory (512 scans being averaged at a resolution of $4 \mathrm{~cm}^{-1}$ ). Spectra were normalized to an average absorbance for the PEG C-O at $1085-1075 \mathrm{~cm}^{-1}$ and then baseline corrected at $1700 \mathrm{~cm}^{-1}$. Amide I band component peak fitting was performed using previously defined parameters [26], and an in-house program built using Omnic Macros Basic (Thermofisher Scientific). Eigen Vector Solo (v7.3.1) was used for principal component analysis (PCA), with all data being mean centered.

\subsection{Neural stem cell (NSC) culture}

Subventricular zone-derived NSCs (CD1 mouse, postnatal day 1 - 3) were propagated as neurospheres based on a widely-used protocol [27]. Dissociated neurospheres were plated as monolayers [on coverslips, sequentially pre-coated with polyornithine then laminin; $2.4 \times 10^{4}$ cells $\mathrm{cm}^{-2}$; monolayer maintenance medium, ML-MM; 1:1 Dulbecco's modified Eagle's medium (DMEM):F12, 1\% N2 supplement, 20 ng mL ${ }^{-1}$ basic fibroblast growth factor (FGF-2) and epidermal growth factor (EGF), $5 \mu \mathrm{g} \mathrm{mL}^{-1}$ heparin, $50 \mathrm{U} \mathrm{mL}^{-1}$ penicillin, $50 \mu \mathrm{g} \mathrm{mL}^{-1}$ streptomycin; $37{ }^{\circ} \mathrm{C}, 5 \% \mathrm{CO}_{2} / 95 \%$ humidified air].

\subsection{Astrocyte, microglial and oligodendrocyte precursor cell cultures}

Primary mixed glial cultures were prepared from dissociated cerebral cortices of Sprague-Dawley rats at postnatal day $1-3$, and high purity glial populations were isolated by sequential rotary shaking procedures using well-established protocols [28]. All mixed glial and high purity cultures were maintained in D10-CM (D10 conditioned medium), composed of D10 medium [DMEM supplemented with $10 \%$ fetal bovine serum (FBS), $2 \mathrm{mM}$ glutaMAX-I, $1 \mathrm{mM}$ sodium pyruvate, $50 \mathrm{U} \mathrm{mL}^{-1}$ penicillin, and $50 \mu \mathrm{g} \mathrm{mL} \mathrm{m}^{-1}$ streptomycin] supplemented with $20 \%$ conditioned medium from parent mixed glial cultures [29]. All cultures were incubated at $37{ }^{\circ} \mathrm{C}$ in $5 \% \mathrm{CO}_{2} / 95 \%$ humidified air. Cells were plated $\left(6 \times 10^{4}\right.$ cells $\left.\mathrm{cm}^{-2}\right)$ on poly-D-lysine (PDL) coated coverslips in 24-well plates.

\subsection{Neuronal culture}

Cerebral cortical tissue was derived from CD1 mice (embryonic day 18) then mechanically and enzymatically (trypsin) dissociated. Dissociated tissue was plated on nitric acid-washed PDL-coated 
coverslips in 24-well plates $\left(3.2 \times 10^{4}\right.$ cells $\left.\mathrm{cm}^{-2}\right)$. Medium (Neurobasal medium, 1\% FBS, $2 \%$ B27 supplement, $2 \mathrm{mM}$ glutaMAX-I, $50 \mathrm{U} \mathrm{mL}^{-1}$ penicillin, $50 \mu \mathrm{g} \mathrm{mL} \mathrm{L}^{-1}$ streptomycin, $250 \mathrm{ng} \mathrm{mL}^{-1}$ amphotericin $\mathrm{B} ; 37^{\circ} \mathrm{C}, 5 \% \mathrm{CO}_{2} / 95 \%$ humidified air) was refreshed every $2-3 \mathrm{~d}$.

\subsection{MNP incubation protocols}

During pilot studies, a concentration of $2 \mu \mathrm{g} \mathrm{mL}^{-1}$ did not produce obvious adverse effects in any cell type, and permitted reliable identification of labelled/unlabeled cells, so was used in all experiments described here. For microglia, astrocytes and OPCs, MNPs were added in fresh medium $24 \mathrm{~h}$ after plating, and incubated with the cells for $24 \mathrm{~h}$. As pilot experiments showed very limited particle uptake by NSCs and neurons, a magnetic field was applied, as such an approach has been shown to enhance MNP uptake [30]. MNPs in fresh medium were added to NSCs (24 h post-plating) and neurons ( $7 \mathrm{~d}$ post-plating), and the culture plate was positioned directly above an oscillating magnetic array (magnefect-nano, nanoTherics Ltd., Stoke-on-Trent, UK) within the incubator. These magnets match the 24-well arrangement of the culture plate, and can be programmed to oscillate with defined frequency and amplitude along a horizontal axis. A frequency of $4 \mathrm{~Hz}$ and amplitude of $200 \mu \mathrm{m}$ are effective for MNP-based transfection of NSCs, so these settings were also used here. After $30 \mathrm{~min}$, the plate was then removed from the magnetic field. At $24 \mathrm{~h}$ post-particle addition, all cultures were washed three times with phosphate buffered saline (PBS) and fixed [4\% paraformaldehyde; room temperature (RT); $25 \mathrm{~min}]$.

\subsection{Immunocytochemistry}

Fixed cells were incubated with blocker (5\% serum in PBS, with $0.3 \%$ Triton X-100 for GFAP and nestin; RT; $30 \mathrm{~min}$ ), then primary antibody or lectin (1:150) in blocker (GFAP 1:500; lectin 1:150; nestin 1:200; NG2 1:200; $4^{\circ} \mathrm{C}$; overnight). Cells were then washed (PBS), incubated with blocker (RT; 30 min), and incubated with the appropriate FITC-conjugated secondary antibody in blocker (1:200; RT; 2 h). Finally, coverslips were washed (PBS) and mounted with the nuclear stain DAPI.

\subsection{Fluorescence microscopy and MNP uptake quantification}


Immunostained samples were imaged using an Axio Scope A1 fluorescence microscope (Carl Zeiss MicroImaging, Germany) and counterpart micrographs merged using Photoshop CS3 (Adobe, USA). Z stack imaging was performed using a Nikon Eclipse 80i microscope fitted with a CA742-95 camera (Hamamatsu Photonics, Japan) with manual focus stepping at $0.5 \mu \mathrm{m}$ (images manipulated using Nikon NIS Elements, version 3.00). A minimum of three microscopic fields and 100 nuclei per culture were assessed for all conditions. Cellular toxicity was assessed by morphological observations, culture purity (percentage of cells immunostained for relevant markers), and percentage of pyknotic nuclei (identified as small, intensely-stained, often fragmenting). Extent of particle uptake was quantified using an integrated density function (ImageJ, NIH, US). Individual MNP-labeled cells were delineated (using immunostained or phase micrographs), then this outline was transferred to the corresponding red channel (MNP) micrograph and the integrated density measured (minimum of 30 MNP-labeled cells per condition per culture, with background intensity subtracted for each image).

\subsection{Statistical analysis}

Data were analyzed using Prism statistical analysis software (GraphPad, USA), and expressed as mean \pm SEM. The number of experiments $(n)$ refers to the number of rat mixed glial cultures from which astrocyte, microglial or OPC cultures were derived, or the number of mouse litters from which NSCs were derived. Each primary culture was established from a different litter. Amide I areas of particle coronas were compared by one-way ANOVA with Bonferroni's multiple comparison post-tests for post-hoc analysis. Unpaired two-tailed $t$-tests were performed for each cell type to compare the following in CMX-MNP versus PEG-MNP-treated cultures: (i) the percentage of MNPlabeled cells, (ii) the mean cellular integrated density value (measurements were averaged per culture), (iii) the percentage of pyknotic nuclei (pyknotic divided by healthy-plus-pyknotic) and (iv) culture purity. 


\section{Results and Discussion}

The two nanoparticle types employed in this study are compared in Figure 2. The coatings chosen were carboxymethyl dextran (CMX-MNP) and diphosphate PEG chains (PEG-MNP). The PEG polymer chosen has been shown previously to reduce protein immunogenicity and enhance blood circulatory time [31-33]. CMX was selected as the control coating as it is a commonly used biocompatible material for pharmaceutics/nanomedicines providing a negative charge similar to the PEGylated particles deployed here [34-37]. These commercial nanoparticles having magnetic (magnetite) cores with a lipophilic dye (BODIPY) overcoated with either a PEG or CMX layer were obtained from Chemicell GmbH (Berlin, Germany). FTIR analyses confirmed the chemical identity of the nanoparticle coatings (Figure 2C). Common to both particles were aliphatic $\mathrm{C}-\mathrm{H}_{\text {str }}$ at $\sim 2950 \mathrm{~cm}^{-1}$, a sharp carboxyl band $\mathrm{C}=\mathrm{O}_{\text {str }}$ at $\sim 1730 \mathrm{~cm}^{-1}$ and $\mathrm{C}-\mathrm{O}_{\text {str }}$ at $\sim 1150$ and $1000 \mathrm{~cm}^{-1}$ consistent with the CMX coating. Additional bands in the region 1250$1000 \mathrm{~cm}^{-1}$ indicate the presence of the phosphate stretches, confirming the PEGylation of the PEG-MNPs [38], as shown in Figure 2C. 

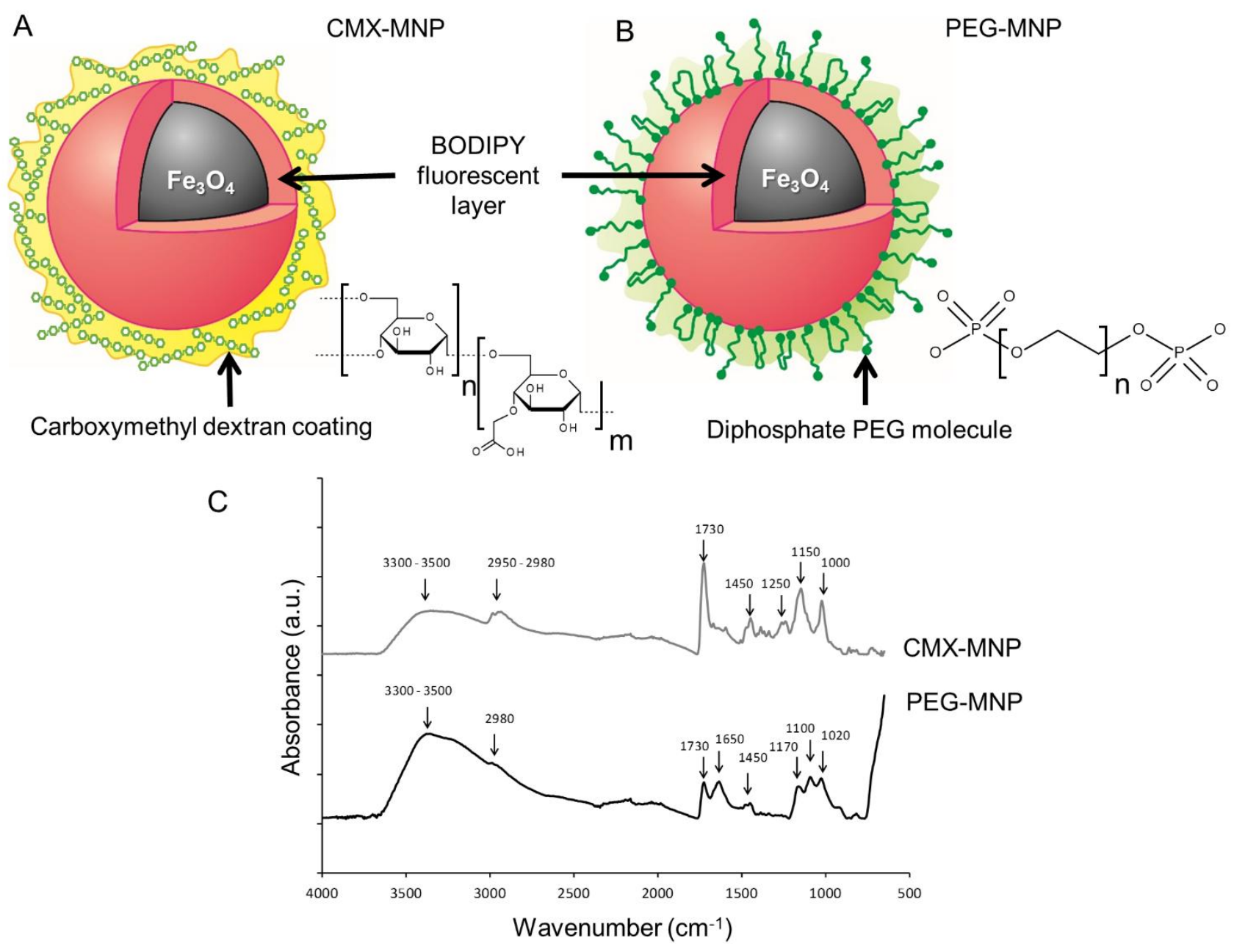

Figure 2. Nanoparticles deployed in this study differ in their surface coatings, identified as carboxymethyl dextran and PEG. (A) Schematics of both MNPs employed here. 'Control' CMX-MNPs are coated with carboxymethyl dextran and 'stealth' PEG nanoparticles are coated with diphosphate polyethylene glycol. (B) FTIR analyses confirmed the presence of carboxymethyl dextran and PEG on the respective nanoparticles.

As biomolecular coronas form around nanomaterials in biological media [39,40], it was deemed essential to conduct particle characterization following incubation in the neural cell specific culture media used to propagate the cell types studied here (termed D10-CM and ML-MM). These two media are necessary to support the survival of functionally specialized neural cell types [41-43]; it should be noted that no single medium is known to support the growth of the entire range of neural cell types. D10-CM contains $10 \%$ fetal bovine serum and $20 \%$ conditioned medium from a mixed glial cell preparation (a complex mixture of 
molecules released by astrocytes, OPCs and microglial cells). ML-MM is a chemically-defined, serum-free preparation. Particle characterization measurements of bare nanoparticles are commonly conducted in PBS/deionized water $[44,45]$, but cannot address alterations in particle properties that occur in complex biological growth media, which are of higher predictive value for the in vivo situation.

However, to characterize the naked particles, dynamic light scattering (DLS) and zeta potential measurements were performed for particles in deionized water, prior to addition to media: CMX being $172 \pm$ $30 \mathrm{~nm},-33.9 \pm 0.8 \mu \mathrm{V}$; PEG being $150 \pm 33 \mathrm{~nm}$ and $-39.6 \pm 0.7 \mu \mathrm{V}(n=3 ; \pm$ standard error of the mean $)$. For biological media, a $24 \mathrm{~h}$ time-point was included in the characterization as this was the total duration of cell exposure to particles, however endocytotic uptake of nanoparticles occurs much earlier, with particle internalization evident one-to-four hours post-particle addition, depending on cell type [22,46,47]. DLS measurements for CMX control and PEG nanoparticles within each cell-specific medium are shown in Table 1, and indicate colloidal stability within $24 \mathrm{~h}$, consistent with previous findings addressing protein adsorption onto nanoparticles [48]. Slightly larger aggregates were formed in the ML-MM versus D10-CM medium (and the biological media versus water) which is likely to be related to the formation of small nanoparticle aggregates (rather than protein corona-induced size increases). 
Table 1. Hydrodynamic diameter and zeta potential for CMX- and PEG-coated nanoparticles in different culture media, used to propagate specific neural cell types.

\begin{tabular}{|c|c|c|c|c|c|c|}
\hline \multirow[t]{2}{*}{ Medium } & \multirow{2}{*}{$\begin{array}{l}\text { Relevant } \\
\text { Cell Type }\end{array}$} & \multirow[t]{2}{*}{ MNP } & \multicolumn{2}{|c|}{$d_{\text {DLS }}(\mathbf{n m} \pm \mathrm{SEM})$} & \multicolumn{2}{|c|}{ Zeta-potential $(\mathrm{mV} \pm \mathrm{SEM})$} \\
\hline & & & $5 \mathrm{~min}$ & $24 \mathrm{~h}$ & $5 \mathrm{~min}$ & $24 \mathrm{~h}$ \\
\hline D10-CM & all glia & CMX & $471 \pm 71$ & $487 \pm 40$ & $-11.1 \pm 0.4$ & $-11.6 \pm 0.4$ \\
\hline D10-CM & all glia & PEG & $481 \pm 106$ & $419 \pm 22$ & $-11.1 \pm 0.6$ & $-10.6 \pm 0.3$ \\
\hline ML-MM & NSCs & CMX & $776 \pm 64$ & $1339 \pm 43$ & $-11.8 \pm 0.4$ & $-11.0 \pm 0.4$ \\
\hline ML-MM & NSCs & PEG & $717 \pm 112$ & $1000 \pm 40$ & $-9.6 \pm 0.5$ & $-11.1 \pm 0.2$ \\
\hline
\end{tabular}

See methods for composition of media; D10-CM = D10 medium containing 20\% conditioned D10 medium from mixed glial cultures; DLS = dynamic light scattering, providing hydrodynamic diameter; ML-MM = monolayer maintenance medium for NSCs; MNP = magnetic nanoparticle; $\mathrm{NSC}=$ neural stem cell; $\mathrm{SEM}=$ standard error of the mean. $n \geq 3$.

Having evaluated the physicochemical properties for the two nanoparticles, detailed assessments were made of the particle corona composition in different culture media. DRIFT analysis of MNP-corona composites, and further processing of data via PCA, demonstrated clear differences between coronas associated with CMX- and PEG-MNPs (Figure 3A-B). Spectra showed variation in amide I band shape and size (Figure 3 A-B) indicating differences in protein structure and amount of adsorbed protein, respectively. This absorption band is indicative of carbonyl stretching, with distinct changes in shape being commonly assigned to protein secondary structure. Semi-quantitative analyses showed differences in terms of the relative amide I band areas, further suggesting differences in quantities of protein bound to each type of MNP, for both media tested (Figure 3C). Compared to PEG nanoparticles, semi-quantitative measurements revealed eight-fold (ML-MM) to 20-fold (D10-CM) greater quantities of protein associated with the control MNPs. The smaller quantity of protein associated with PEG-MNPs is consistent with the proposed molecular mechanism of action for 'stealth' coatings which can exert a significant influence on cellnanoparticle interactions [49-53]. 


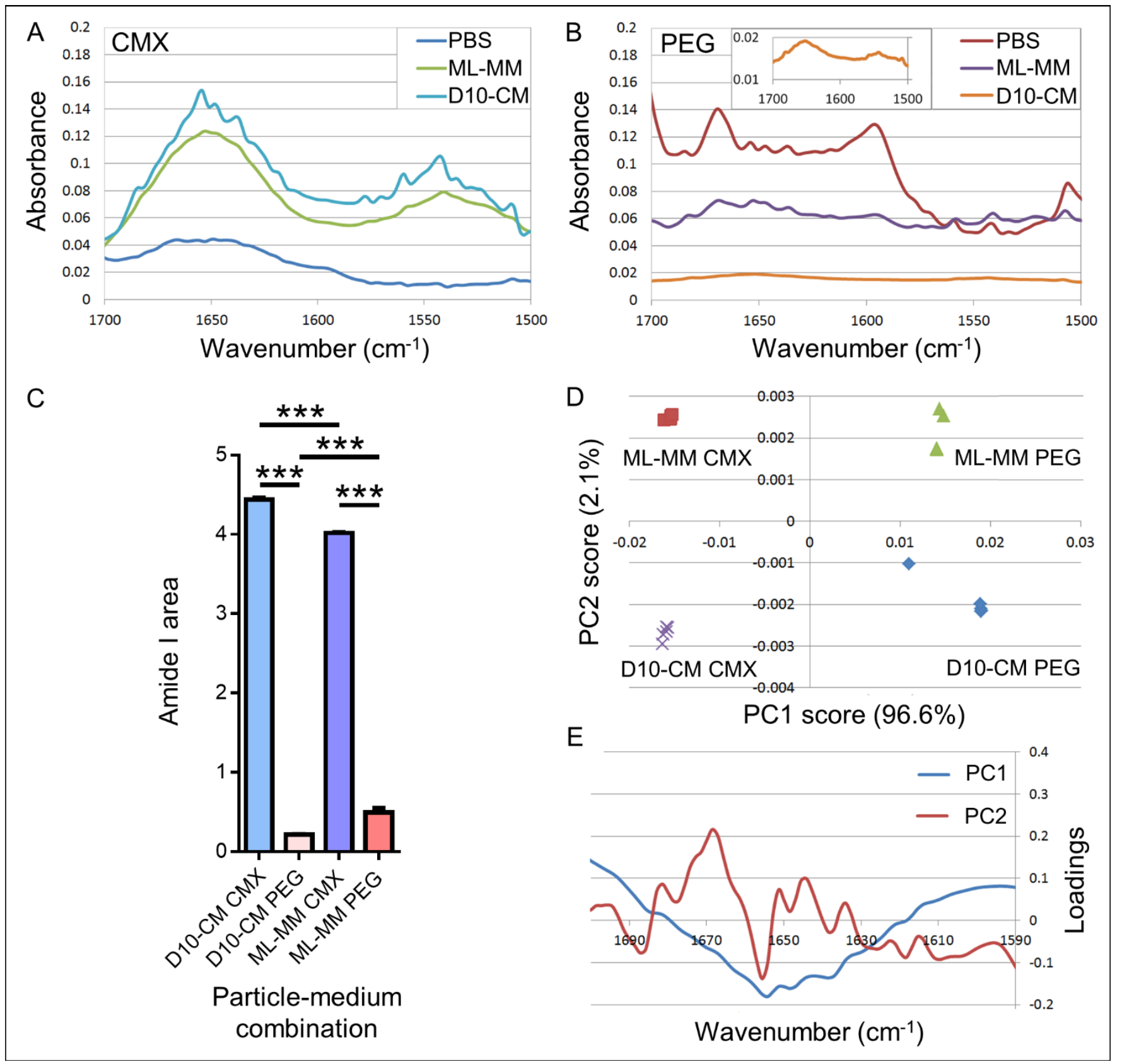

Figure 3. In cell-specific culture media, PEGylated MNPs display a quantitatively and qualitatively different biomolecular corona compared to control MNPs. DRIFT analysis of CMX-(A) and PEG-MNPs (B) in saline (PBS) and two culture media. (C) Semi-quantitative assessment of amide I region illustrating limited biomolecule aggregation around PEGylated nanoparticles versus control nanoparticles in two different culture media. One-way ANOVA with Bonferroni's post-tests; ***p $<0.001$. (D) Principal component (PC) analysis reveals consistency of properties across four replicates, and distinct differences between PEGylated and control MNPs within each medium, as well as between media. (E) Loadings plot of amide I region. D10-CM = conditioned glial culture medium; $M L-M M=$ monolayer maintenance medium; $P B S=$ phosphate buffered saline. 
PCA analysis confirmed secondary structural differences with tight clustering of data sets, discriminating between particle types (CMX-MNPs and PEG-MNPs; PC1) and the media used (i.e. D10 CMX versus ML CMX, and D10 PEG versus ML PEG; PC2; Figure 3D). PC loadings suggest most variance is related to protein secondary structural differences. This is indicated by the $\alpha$-helical and $\beta$-sheet components in the region 1700-1600 cm-1 (Figure 3E). Such differences in protein conformation are expected, due to adsorption induced structural changes [26]. However, due to the plethora of proteins likely adsorbed onto the nanoparticles it is only possible to make a global assessment of protein structure rather than to discriminate between actual protein conformation changes, i.e. protein composition is likely to also vary between particle/media types. Our future mass spectrometric analyses aim to dissect these differences further.

For all the cellular uptake experiments, we relied exclusively on cells of primary origin. We have described elsewhere how cells derived from a primary source may typically be expected to provide data with greater biological relevance than cell lines, as the latter (i) often behave in a relatively homogenous, clonal manner, (ii) can mask toxicity through resistance to cell death stimuli, and (iii) can exhibit greater levels of particle uptake than 'equivalent' primary cells [22]. High purity cultures were routinely derived in our experiments for each neural cell type, as judged by immunostaining for cell-specific markers (microglial cultures were $>95 \%$ lectin-reactive, $n=4$; astrocyte cultures were $>95 \% \mathrm{GFAP}^{+}, n=4$; OPC cultures were $>94 \% \mathrm{NG}^{+}, n$ $=4$; NSC cultures were $>98 \%$ nestin $^{+}, n=5$; neuronal cultures were $c a .70 \%$ Tuj $1^{+}, n=2$ ).

Fluorescence microscopy, including z-stack analyses, confirmed the intracellular localization of both CMXand PEG-MNPs by each neural cell type (Figure 4). For each particle, the same cellular hierarchy was apparent in terms of extent of uptake, consistent with our previous report [22]: microglia > astrocytes > OPCs > NSCs. A negligible percentage $(<0.5 \%)$ of primary mouse cortical neurons exhibited uptake of either particle type (Figure 4I-J) placing these cells at the bottom of the cellular hierarchy. The percentage of cells labeled and the extent of uptake were not sufficient for a reliable statistical comparison between the two particle types, and were therefore excluded from further analyses. For all cells, particles were clearly observed within the cytoplasm, with distinctive arc-like accumulations around the nuclear perimeter (Figure 
4A-H). No nanoparticles were observed to be intranuclear, or within the fine cellular processes, in any cell type.

Quantification of (i) the percentage of cells exhibiting MNP-labeling, and (ii) the extent of MNP-loading per cell, revealed significant differences between cell types and also between the two nanoparticles with respect to all cell types except neurons (Figure 5). There were no differences in the proportions of MNP-labeled microglia or OPCs, while for astrocytes and NSCs, a smaller proportion of cells exhibited PEG-MNPlabeling versus CMX-MNP-labeling (Figure 5A). However, dramatic differences in extent of cellular accumulation of stealth nanoparticles were revealed by integrated density measurements. All cell types demonstrated a reduction in the extent of PEG-MNP uptake compared to CMX-MNPs (Figure 5B). Heavily labeled microglia often exhibited rounded morphologies, consistent with microglial activation, exhibiting less-branched morphologies than those with smaller accumulations.

No toxic effects were noted for either control or PEGylated nanoparticles across all cell types (Figure 5CD). The procedures appear to be safe, as all morphological evaluations through microscopic analyses revealed normal-appearing, healthy and rounded nuclei with normal patterns of expression of cell-specific markers, and no evidence of cellular detachment from the substrate, all robust indicators of viability. Unaltered percentage expression of cell-specific markers suggests no short term effects on differentiation profiles or particle-induced aberrant marker expression. For all cells, the percentage of nuclei with pyknotic features (shrunken and fragmenting nuclei, indicating cell death) did not differ between particle types, and these values were in accordance with previously reported values from untreated cultures [22,27,54]; typical nuclear and cellular morphological features were observed across all cultures (Figure 4). 


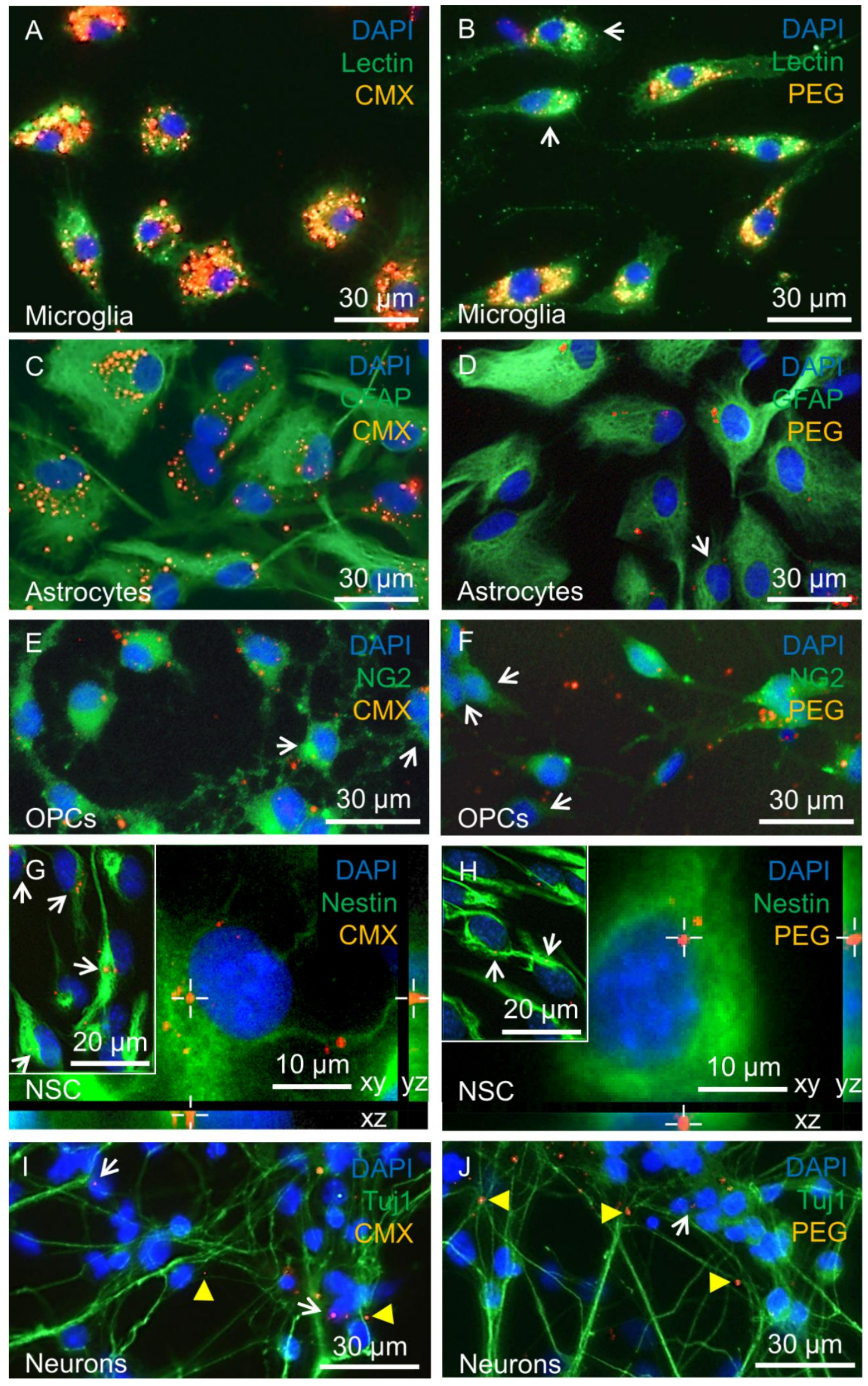

Figure 4. Extent of particle uptake varies greatly between neural cell types, and PEGylated nanoparticles are less avidly taken up than CMX-coated nanoparticles. Fluorescence micrographs of high purity cultures 
following incubation with CMX- or PEG-coated fluorescent magnetic nanoparticles (24 h). Figures show DAPI-stained nuclei as blue, cell bodies and processes as green, and particles as red. Uptake of CMXMNPs was extensive in the majority of lectin-reactive microglia (A), whereas uptake of PEG-MNPs was more heterogeneous, and often markedly lower, in extent (B; arrows indicate low levels of uptake). For both particle types, astrocytes $\left(G F A P^{+}\right)$exhibited lower levels of uptake than was observed in microglia, with CMX-MNPs $(C)$ taken up more extensively than PEG-MNPs (D; arrow indicates unlabeled astrocyte. For OPCs $\left(N G 2^{+}\right), C M X-M N P$ treatment $(E)$ resulted in a greater percentage of labeled cells, and greater average extent of uptake, compared with PEG-MNP treatment $(F)$; arrows indicate unlabeled OPCs. Uptake by NSCs $\left(\right.$ nestin $\left.^{+}\right)$was confirmed using z stack analyses $(G, H$; note perinuclear accumulation of nanoparticles), and for both particle types NSCs exhibited lower levels of uptake than all other cell types. Consistent with the other cell types, PEG-MNPs were taken up less extensively (H, inset) than CMX-MNPs $(G$, inset); arrows indicate labeled NSCs. For both nanoparticles, a negligible percentage of neurons $\left(T u j 1^{+}\right)$exhibited any uptake $(I, J)$, with these MNP-labelled neurons (arrows) displaying a limited extent of uptake. Yellow arrowheads indicate extracellular MNPs. 
A

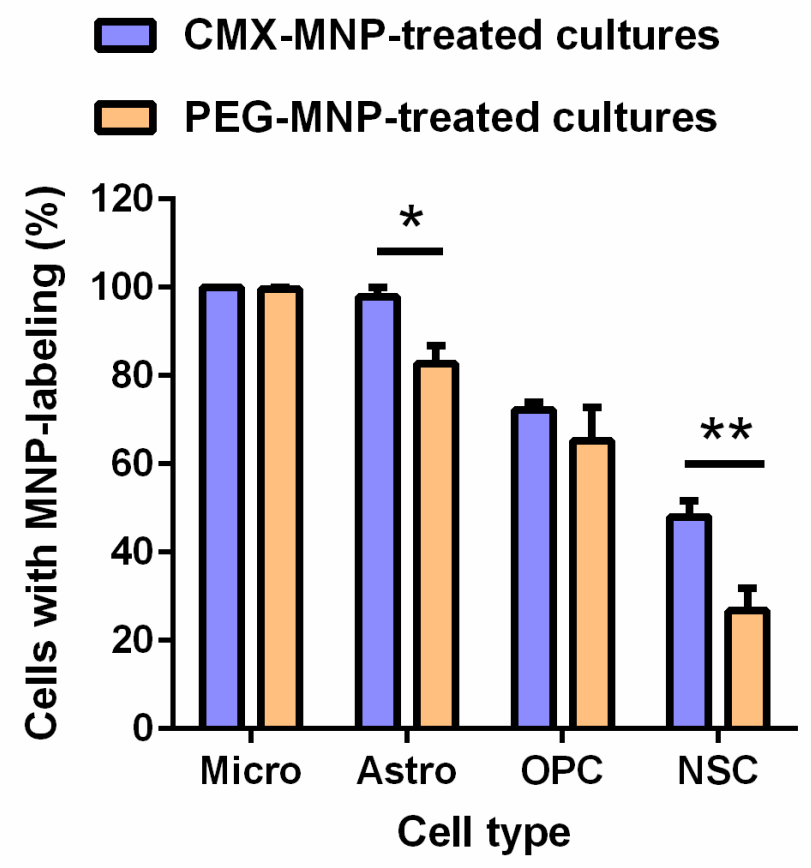

C

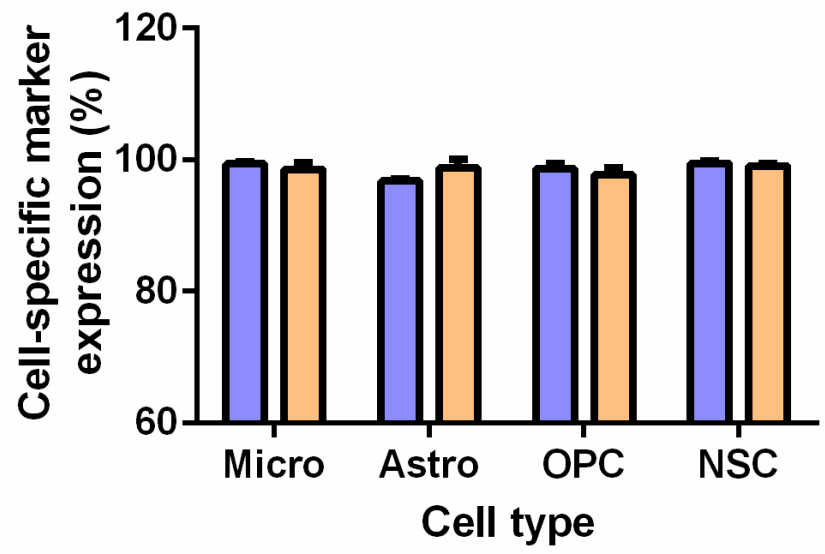

B
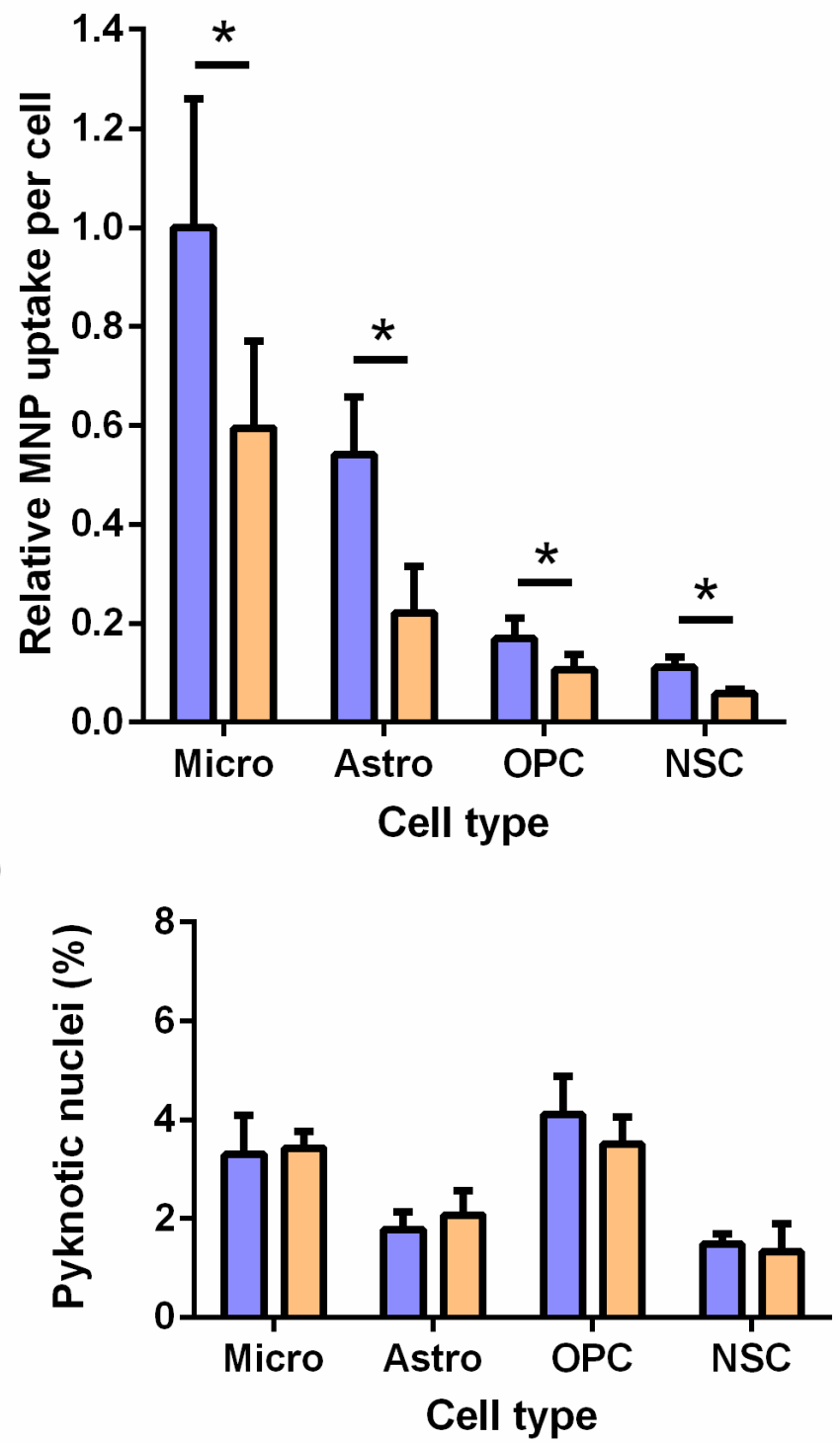

Figure 5. Uptake of PEGylated MNPs is significantly reduced compared to control nanoparticles for various neural cell types. 24 h post-particle addition to high purity cultures of each cell type. Bar graphs indicating (a) the percentage of positively-identified cells with MNP-labeling, $(b)$ the average extent of MNP-loading per cell, assessed by integrated density measurements, (c) culture purity as judged by cellspecific marker expression and (d) percentage of pyknotic nuclei. Paired t tests; CMX-MNP versus PEGMNP; $* p<0.05, * * p<0.01$. Micro = lectin-reactive cells in microglial cultures, $n=4 ;$ Astro $=G F A P^{+}$ cells in astrocyte cultures, $n=4 ; O P C=N G 2^{+}$cells in OPC cultures, $n=4 ; N S C=$ nestin $^{+}$cells in NSC cultures, $n=5$. 
Corona-resistant PEGylated nanoparticles are realizing therapeutic potential for many applications including treatment of neurological injury, although it remains unclear at present how these nanoparticles are handled within the neural milieu. Our results demonstrate for the first time that diphosphate PEGylation is an effective approach to reduce particle clearance by the specialist neural immune cells - the microglia consistent with the broad intended evasive function of 'stealth' coatings. The overwhelming majority of MNP-based delivery strategies to the CNS rely on delivery of particles to the extracellular space, requiring that MNPs efficiently cross the BBB and persist extracellularly within the parenchyma [1]. This strategy has been employed for dalargin, an enkephalin analog that acts on membrane receptors [55,56]. Clearly this approach would be limited by rapid and avid microglial clearance, limiting therapeutic benefit. This is especially pertinent in sites of neurological injury, where inflammatory mechanisms typically result in high densities of activated microglia in neural pathology sites. There is therefore a critical need to enhance and prolong delivery of therapeutic agents to these sites for clinical efficacy. Our observations highlight the high utility of PEGylation strategies to reduce microglial clearance, thereby promoting particle retention and bioavailability within the extracellular space, enhancing therapeutic efficacy overall. Accordingly we suggest that our findings are of high relevance to neuronanotherapeutics in aiding the development of novel nanosystems for direct and systemic biomolecule delivery to neurological pathology sites.

To our knowledge, we are also the first to demonstrate that PEGylation limits particle uptake by all major neural cell types. These data indicate that the non-specific cellular evasion afforded by PEGylation could further prolong bioavailability within the CNS parenchyma, of added benefit for drug delivery. Supporting our findings, one study has reported a similar phenomenon for tumor cells, suggesting that PEGylationinduced steric hindrance may limit uptake by other non-immune cells [57]. PEGylated materials benefit from enhanced bioavailability due to their increased stability within aqueous media, protection from proteolytic degradation, reduced renal clearance, reduced immunogenicity, and increased circulation time within biological fluids due to colloidal stability, whilst limiting concerns related to safety and tolerance $[33,58,59]$. Our characterization of the MNP-associated biomolecular coronas generated in culture media revealed marked differences in the protein coat formed around each of the nanoparticle types, which could 
account for the reduced uptake of PEGylated MNPs by all neural cells. High density PEGylation forms a hydrophilic and steric barrier due to the 'brush-like' surface conformation of PEG chains [49]. Reduction of sites interacting with plasma proteins (e.g. lipoproteins and opsonins), limits immune clearance and increases circulatory half-life/bioavailability $[60,61]$. Further, changes in protein coronas around nanoparticles, including even subtle differences in size, charge and exposure of specific proteins, can alter particle agglomeration or impact biological interactions ultimately affecting uptake of nanoparticles into cells $[62,63]$. Clearly therefore, the physicochemical characteristics of nanomaterials need to be taken into account in terms of uptake, biological trafficking and toxicological effects, particularly with respect to advanced nanoparticle strategies being translated into the clinic.

It should be noted that some therapies depend on nanoparticle delivery to specific target cell populations, for example gene delivery to neurons [64]. Several potential strategies could be considered in such situations to overcome the uptake limitations imposed by PEGylation. Firstly, increasing the administered MNP dose is a common strategy, but this is a non-specific approach and doses required for efficacious uptake within the CNS can be predicted to carry a toxicity risk. The second strategy involves adding targeting ligands to the outer tip of PEG molecules at the particle surface (for example targeted to transferrin and insulin receptors, which are abundant at the BBB, and can facilitate transfer of appropriately-tagged molecules/particles into the CNS parenchyma [65]). However, transferrin receptors are also abundant in the liver - a major MPS component - so targets should be sought with greater BBB specificity. Once across the $\mathrm{BBB}$, ligands to receptors abundant in or exclusive to the target neural cell type are required; it should be noted that there is a serious lack of available neural cell targeting molecules currently, limiting this approach. Targeting could also be achieved through manipulation of the specific protein constituents of the corona (by designing the particle surface to specifically bind and expose certain biomolecules). Lastly, other types of stealth coatings require investigation. For example, nanoparticles with zwitterionic coatings reduce the rate of non-specific binding for proteins and lipids [66]. Based on peptides with an overall zero charge, zwitterionic coatings are biocompatible and would be suitable for evading immune components. Other coatings, such as derivatives of poly(carboxybetaine), poly(sulfobetaine) and poly(acrylic acid; PAA), have also been used as stealth coatings for nanoparticles but all of the above are untested in neural cells. Using our approach to perform a 
systematic wide-scale screen of MNPs with diverse stealth coatings versus PEGylated MNPs could yield important results in this context. However, if the reduced protein corona and related alterations in the physicochemical properties of such 'stealth' MNPs is the only mechanism by which these MNPs evade immune components, then it can be assumed that novel 'stealth' coatings will continue to evade nonimmune neural cell types. Indeed the similarity in observations of PEGylated MNP evasion across cell types suggests the operation of a ubiquitous nanoparticle internalization mechanism such as micropinocytosis, mediating uptake of the nanoparticles used here. However, we suggest based on our findings that the pancellular evasion induced by PEGylation of nanoparticles could be readily exploited for drug delivery to the brain. 


\section{Author Contributions}

The manuscript was written through contributions of all authors. All authors have given approval to the final version of the manuscript. ${ }^{\star}$ These authors contributed equally.

\section{Acknowledgements}

We thank R Fricker and M Gates for access to z stack microscopy facilities (Keele University). SJ is funded by an Engineering and Physical Sciences Research Council (EPSRC; UK) Engineering Tissue Engineering and Regenerative Medicine (E-TERM) Landscape Fellowship (EP/I017801/1).
Abbreviations
BBB, blood-brain barrier; CMX, carboxymethyl dextran; CNS, central nervous system; D10, glial culture medium; DAPI, 4',6-diamidino-2-phenylindole; DRIFT, diffuse reflection infrared Fourier transform spectroscopy; FITC, fluorescein isothiocyanate; FTIR, Fourier transform infrared spectroscopy; GFAP, glial fibrillary acidic protein; ML-MM, monolayer maintenance medium; MNP, magnetic nanoparticle; NSC, neural stem cell; OPC, oligodendrocyte precursor cell; PBS, phosphate buffered saline; PCA, principal component analysis; PDL, poly-D-lysine; PEG, polyethylene glycol; RT, room temperature. 


\section{References}

[1] S. Wohlfart, S. Gelperina, J. Kreuter, Transport of drugs across the blood-brain barrier by nanoparticles., J. Control. Release. 161 (2012) 264-73. doi:10.1016/j.jconrel.2011.08.017.

[2] Y. Cheng, R.A. Morshed, B. Auffinger, A.L. Tobias, M.S. Lesniak, Multifunctional nanoparticles for brain tumor imaging and therapy., Adv. Drug Deliv. Rev. 66 (2014) 42-57.

doi:10.1016/j.addr.2013.09.006.

[3] S. Krol, Challenges in drug delivery to the brain: nature is against us., J Control Release. 164 (2012) 145-55. doi:10.1016/j.jconrel.2012.04.044.

[4] P. Calvo, B. Gouritin, H. Chacun, D. Desmaile, J. D’Angelo, J.P. Noel, et al., Long-circulating pegylated polycyanoacrylate nanoparticles as new drug carrier for brain delivery, Pharm. Res. 18 (2001) 1157-1166. doi:10.1023/A:1010931127745.

[5] M.A. Dobrovolskaia, P. Aggarwal, J.B. Hall, S.E. McNeil, Preclinical studies to understand nanoparticle interaction with the immune system and its potential effects on nanoparticle biodistribution, Mol. Pharm. 5 (2008) 487-495.

[6] Wahajuddin, S. Arora, Superparamagnetic iron oxide nanoparticles: Magnetic nanoplatforms as drug carriers, Int. J. Nanomedicine. 7 (2012) 3445-3471. doi:10.2147/IJN.S30320.

[7] M. De Bock, R.E. Vandenbroucke, E. Decrock, M. Culot, R. Cecchelli, L. Leybaert, A new angle on blood-CNS interfaces: a role for connexins?, FEBS Lett. 588 (2014) 1259-70.

doi:10.1016/j.febslet.2014.02.060.

[8] D.J. Begley, Delivery of therapeutic agents to the central nervous system: the problems and the possibilities., Pharmacol. Ther. 104 (2004) 29-45. doi:10.1016/j.pharmthera.2004.08.001.

[9] P.A. Nielsen, O. Andersson, S.H. Hansen, K.B. Simonsen, G. Andersson, Models for predicting blood-brain barrier permeation., Drug Discov. Today. 16 (2011) 472-5.

doi:10.1016/j.drudis.2011.04.004.

[10] T. Cedervall, I. Lynch, S. Lindman, T. Berggård, E. Thulin, H. Nilsson, et al., Understanding the nanoparticle-protein corona using methods to quantify exchange rates and affinities of proteins for nanoparticles., Proc. Natl. Acad. Sci. U. S. A. 104 (2007) 2050-5. doi:10.1073/pnas.0608582104.

[11] D. Walczyk, F.B. Bombelli, M.P. Monopoli, I. Lynch, K.A. Dawson, What the cell "sees" in bionanoscience., J. Am. Chem. Soc. 132 (2010) 5761-5768. doi:10.1021/ja910675v.

[12] I. Lynch, T. Cedervall, M. Lundqvist, C. Cabaleiro-Lago, S. Linse, K.A. Dawson, The nanoparticleprotein complex as a biological entity; a complex fluids and surface science challenge for the $21 \mathrm{st}$ century., Adv. Colloid Interface Sci. 134-135 (2007) 167-74. doi:10.1016/j.cis.2007.04.021.

[13] L. Zhang, F.X. Gu, J.M. Chan, A.Z. Wang, R.S. Langer, O.C. Farokhzad, Nanoparticles in Medicine : 
Therapeutic Applications and Developments, 83 (2008) 761-769. doi:10.1038/sj.clp.

[14] R. Lehner, X. Wang, S. Marsch, P. Hunziker, Intelligent nanomaterials for medicine: carrier platforms and targeting strategies in the context of clinical application., Nanomedicine. 9 (2013) 74257. doi:10.1016/j.nano.2013.01.012.

[15] H.R. Kim, K. Andrieux, S. Gil, M. Taverna, D. Georgin, P. Couvreur, Translocation of Poly(ethylene glycol-co-hexadecyl) cyanoacrylate Nanoparticles into Rat Brain Endothelial Cells: Role of Apolipoproteins in receptor-mediated endocytosis, Biomacromolecules. 8 (2007) 793-799.

[16] E.A. Nance, G.F. Woodworth, K.A. Sailor, T.-Y. Shih, Q. Xu, G. Swaminathan, et al., A Dense Poly(Ethylene Glycol) Coating Improves Penetration of Large Polymeric Nanoparticles Within Brain Tissue, Sci. Transl. Med. 4 (2012) 149ra119-149ra119. doi:10.1126/scitranslmed.3003594.

[17] I. Brigger, J. Morizet, G. Aubert, H. Chacun, M.-J. Terrier-Lacombe, P. Couvreur, et al., Poly(ethylene glycol)-coated hexadecylcyanoacrylate nanospheres display a combined effect for brain tumor targeting, J. Pharmacol. Exp. Ther. 303 (2002) 928-936. doi:10.1124/jpet.102.039669.thelial.

[18] P. Calvo, B. Gouritin, H. Villarroya, F. Eclancher, C. Giannavola, C. Klein, et al., Quantification and localization of PEGylated polycyanoacrylate nanoparticles in brain and spinal cord during experimental allergic encephalomyelitis in the rat, Eur J Neurosci. 15 (2002) 1317-1326.

[19] H. Maeda, J. Fang, T. Inutsuka, Y. Kitamoto, Vascular permeability enhancement in solid tumor: Various factors, mechanisms involved and its implications, Int. Immunopharmacol. 3 (2003) 319328. doi:10.1016/S1567-5769(02)00271-0.

[20] M. Prinz, J. Priller, Microglia and brain macrophages in the molecular age: from origin to neuropsychiatric disease., Nat. Rev. Neurosci. 15 (2014) 300-12. doi:10.1038/nrn3722.

[21] D. Nayak, T.L. Roth, D.B. McGavern, Microglia development and function., Annu. Rev. Immunol. 32 (2014) 367-402. doi:10.1146/annurev-immunol-032713-120240.

[22] S.I. Jenkins, M.R. Pickard, D.N. Furness, H.H.P. Yiu, D.M. Chari, Differences in magnetic particle uptake by CNS neuroglial subclasses: implications for neural tissue engineering., Nanomedicine (Lond.). 8 (2013) 951-68. doi:10.2217/nnm.12.145.

[23] G. Fleige, C. Nolte, M. Synowitz, F. Seeberger, H. Kettenmann, C. Zimmer, Magnetic labeling of activated microglia in experimental gliomas., Neoplasia. 3 (2001) 489-99.

doi:10.1038/sj/neo/7900176.

[24] S.I. Jenkins, H.H.P. Yiu, M.J. Rosseinsky, D.M. Chari, Magnetic nanoparticles for oligodendrocyte precursor cell transplantation therapies: progress and challenges, Mol. Cell. Ther. 2 (2014) 23. doi:10.1186/2052-8426-2-23.

[25] T. Jain, J. Richey, M. Strand, D.L. Leslie-Pelecky, C. Flask, V. Labhasetwar, Magnetic nanoparticles with dual functional properties: drug delivery and magnetic resonance imaging, Biomaterials. 29 (2008) 4012-4021. doi:10.1016/j.biomaterials.2008.07.004.Magnetic. 
[26] P. Roach, D. Farrar, C.C. Perry, Surface tailoring for controlled protein adsorption: effect of topography at the nanometer scale and chemistry., J. Am. Chem. Soc. 128 (2006) 3939-45. doi:10.1021/ja056278e.

[27] C.F. Adams, M.R. Pickard, D.M. Chari, Magnetic nanoparticle mediated transfection of neural stem cell suspension cultures is enhanced by applied oscillating magnetic fields., Nanomedicine NBM. 9 (2013) 737-41. doi:10.1016/j.nano.2013.05.014.

[28] K.D. McCarthy, J. de Vellis, Preparation of separate astroglial and oligodendroglial cell cultures from rat cerebral tissue., J. Cell Biol. 85 (1980) 890-902. http://www.ncbi.nlm.nih.gov/pubmed/6248568.

[29] S.I. Jenkins, P. Roach, D.M. Chari, Development of a nanomaterial bio-screening platform for neurological applications., Nanomedicine NBM. (2014) 1-10. doi:10.1016/j.nano.2014.07.010.

[30] S.I. Jenkins, M.R. Pickard, N. Granger, D.M. Chari, Magnetic nanoparticle-mediated gene transfer to oligodendrocyte precursor cell transplant populations is enhanced by magnetofection strategies., ACS Nano. 5 (2011) 6527-6538. doi:10.1021/nn2018717.

[31] S. Lee, Y.S. Youn, S.H. Lee, Y. Byun, K.C. Lee, PEGylated glucagon-like peptide-1 displays preserved effects on insulin release in isolated pancreatic islets and improved biological activity in db/db mice, Diabetologia. 49 (2006) 1608-1611. doi:10.1007/s00125-006-0234-3.

[32] A. Abuchowski, T. van Es, N.C. Palczuk, F.F. Davis, Alteration of Immunological Properties of Bovine Serum Albumin by Covalent Attachment of Polyethylene Glycol, Journal. 252 (1977) 35783581 .

[33] J.S. Kang, P.P. Deluca, K.C. Lee, Emerging PEGylated drugs., Expert Opin. Emerg. Drugs. 14 (2009) 363-380. doi:10.1517/14728210902907847.

[34] R. Mehvar, Dextrans for targeted and sustained delivery of therapeutic and imaging agents, J Control Release. 69 (2000) 1-25.

[35] H. Guo, W. Chen, X. Sun, Y.-N. Liu, J. Li, J. Wang, Theranostic magnetoliposomes coated by carboxymethyl dextran with controlled release by low-frequency alternating magnetic field, Carbohydr. Polym. 118 (2015) 209-217. doi:10.1016/j.carbpol.2014.10.076.

[36] T. Koyama, M. Shimura, Y. Minemoto, S. Nohara, S. Shibata, Y. Iida, et al., Evaluation of selective tumor detection by clinical magnetic resonance imaging using antibody-conjugated superparamagnetic iron oxide, J. Control. Release. 159 (2012) 413-418. doi:10.1016/j.jconrel.2012.01.023.

[37] D.E. Sosnovik, M. Nahrendorf, Cells and Iron Oxide Nanoparticles on the Move: Magnetic Resonance Imaging of Monocyte Homing and Myocardial Inflammation in Patients With STElevation Myocardial Infarction, Circ. Cardiovasc. Imaging. 5 (2012) 551-554. doi:10.1161/CIRCIMAGING.112.978932. 
[38] C. Lu, L.R. Bhatt, H.Y. Jun, S.H. Park, K.Y. Chai, Carboxyl-polyethylene glycol-phosphoric acid: a ligand for highly stabilized iron oxide nanoparticles, J. Mater. Chem. 22 (2012) 19806.

doi:10.1039/c2jm34327d.

[39] M. Safi, J. Courtois, M. Seigneuret, H. Conjeaud, J.-F. Berret, The effects of aggregation and protein corona on the cellular internalization of iron oxide nanoparticles., Biomaterials. 32 (2011) 9353-63. doi:10.1016/j.biomaterials.2011.08.048.

[40] A.L. Barrán-Berdón, D. Pozzi, G. Caracciolo, A.L. Capriotti, G. Caruso, C. Cavaliere, et al., Time evolution of nanoparticle-protein corona in human plasma: relevance for targeted drug delivery., Langmuir. 29 (2013) 6485-94. doi:10.1021/la401192x.

[41] S.I. Jenkins, P. Roach, D.M. Chari, Development of a nanomaterial bio-screening platform for neurological applications., Nanomedicine. 11 (2014) 77-87. doi:10.1016/j.nano.2014.07.010.

[42] F.-P. Wachs, S. Couillard-Despres, M. Engelhardt, D. Wilhelm, S. Ploetz, M. Vroemen, et al., High efficacy of clonal growth and expansion of adult neural stem cells., Lab. Invest. 83 (2003) 949-962. doi:10.1097/01.LAB.0000075556.74231.A5.

[43] A.R. Fernandes, D.M. Chari, A multicellular, neuro-mimetic model to study nanoparticle uptake in cells of the central nervous system, Integr. Biol. 6 (2014) 855-861. doi:10.1039/C4IB00085D.

[44] Z. Sun, V. Yathindranath, M. Worden, J.A. Thliveris, S. Chu, F.E. Parkinson, et al., Characterization of cellular uptake and toxicity of aminosilane-coated iron oxide nanoparticles with different charges in central nervous system relevant cell culture models., Int J Nanomed. 8 (2013) 961-70. doi:10.2147/IJN.S39048.

[45] X. Gao, J. Qian, S. Zheng, Y. Xiong, J. Man, B. Cao, et al., Up-regulating blood brain barrier permeability of nanoparticles via multivalent effect., Pharm. Res. 30 (2013) 2538-48. doi:10.1007/s11095-013-1004-9.

[46] M.R. Pickard, S.I. Jenkins, C. Koller, D.N. Furness, D.M. Chari, Magnetic nanoparticle labelling of astrocytes derived for neural transplantation, Tissue Eng., Part C. 17 (2011) 89-99. doi:10.1089/ten.tec.2010.0170.

[47] M.R. Pickard, D.M. Chari, Robust uptake of magnetic nanoparticles (MNPs) by central nervous system (CNS) microglia: implications for particle uptake in mixed neural cell populations., Int. J. Mol. Sci. 11 (2010) 967-981. doi:10.3390/ijms11030967.

[48] V. Hirsch, C. Kinnear, M. Moniatte, B. Rothen-Rutishauser, M.J.D. Clift, A. Fink, Surface charge of polymer coated SPIONs influences the serum protein adsorption, colloidal stability and subsequent cell interaction in vitro., Nanoscale. 5 (2013) 3723-32. doi:10.1039/c2nr33134a.

[49] R. Gref, M. Lück, P. Quellec, M. Marchand, E. Dellacherie, S. Harnisch, et al., "Stealth" corona-core nanoparticles surface modified by polyethylene glycol (PEG): influences of the corona (PEG chain length and surface density) and of the core composition on phagocytic uptake and plasma protein adsorption., Colloids Surf. B. Biointerfaces. 18 (2000) 301-313.

http://www.ncbi.nlm.nih.gov/pubmed/10915952. 
[50] M.A. Dobrovolskaia, B.W. Neun, S. Man, X. Ye, M. Hansen, A.K. Patri, et al., Protein corona composition does not accurately predict hematocompatibility of colloidal gold nanoparticles., Nanomedicine NBM. 10 (2014) 1453-63. doi:10.1016/j.nano.2014.01.009.

[51] E. Mahon, A. Salvati, F. Baldelli Bombelli, I. Lynch, K.A. Dawson, Designing the nanoparticlebiomolecule interface for "targeting and therapeutic delivery"., J. Control. Release. 161 (2012) 16474. doi:10.1016/j.jconrel.2012.04.009.

[52] D. Pozzi, V. Colapicchioni, G. Caracciolo, S. Piovesana, A.L. Capriotti, S. Palchetti, et al., Effect of polyethyleneglycol (PEG) chain length on the bio-nano-interactions between PEGylated lipid nanoparticles and biological fluids: from nanostructure to uptake in cancer cells., Nanoscale. 6 (2014) 2782-92. doi:10.1039/c3nr05559k.

[53] T. Maldiney, C. Richard, J. Seguin, N. Wattier, M. Bessodes, D. Scherman, Effect of core diameter, surface coating, and PEG chain length on the biodistribution of persistent luminescence nanoparticles in mice, ACS Nano. 5 (2011) 854-862. doi:10.1021/nn101937h.

[54] H.H.P. Yiu, M.R. Pickard, C.I. Olariu, S.R. Williams, D.M. Chari, M.J. Rosseinsky, Fe3O4-PEIRITC magnetic nanoparticles with imaging and gene transfer capability: development of a tool for neural cell transplantation therapies, Pharm. Res. 29 (2012) 1328-1343. doi:10.1007/s11095-0110632-1.

[55] U. Schroeder, P. Sommerfeld, B. a. Sabel, Efficacy of oral dalargin-loaded nanoparticle delivery across the blood- brain barrier, Peptides. 19 (1998) 777-780. doi:10.1016/S0196-9781(97)00474-9.

[56] A. Misra, S. Ganesh, A. Shahiwala, S.P. Shah, Drug delivery to the central nervous system: a review., J. Pharm. Pharm. Sci. 6 (2003) 252-73. http://www.ncbi.nlm.nih.gov/pubmed/12935438.

[57] R. Hong, C. Huang, Y. Tseng, Direct Comparison of Liposomal Doxorubicin with or without Polyethylene Glycol Coating in C-26 Tumor-bearing Mice: Is Surface Coating with Polyethylene Glycol Beneficial?, Clin Cancer Res. 5 (1999) 3645-3652.

[58] A.J. Cole, A.E. David, J. Wang, C.J. Galbán, V.C. Yang, Magnetic brain tumor targeting and biodistribution of long-circulating PEG-modified, cross-linked starch-coated iron oxide nanoparticles., Biomaterials. 32 (2011) 6291-301. doi:10.1016/j.biomaterials.2011.05.024.

[59] D. Vllasaliu, R. Fowler, S. Stolnik, PEGylated nanomedicines: recent progress and remaining concerns., Expert Opin. Drug Deliv. 11 (2014) 139-54. doi:10.1517/17425247.2014.866651.

[60] C.D. Walkey, W.C.W. Chan, Understanding and controlling the interaction of nanomaterials with proteins in a physiological environment, Chem. Soc. Rev. 41 (2012) 2780-2799. doi:10.1039/C1CS15233E.

[61] D. V. Santi, E.L. Schneider, R. Reid, L. Robinson, G.W. Ashley, Predictable and tunable half-life extension of therapeutic agents by controlled chemical release from macromolecular conjugates, Proc. Natl. Acad. Sci. 109 (2012) 6211-6216. doi:10.1073/pnas.1117147109. 
[62] M. Lundqvist, J. Stigler, T. Cedervall, T. Berggård, M.B. Flanagan, I. Lynch, et al., The evolution of the protein corona around nanoparticles: a test study., ACS Nano. 5 (2011) 7503-9.

doi:10.1021/nn202458g.

[63] C. Brandenberger, C. Mühlfeld, Z. Ali, A.G. Lenz, O. Schmid, W.J. Parak, et al., Quantitative evaluation of cellular uptake and trafficking of plain and polyethylene glycol-coated gold nanoparticles, Small. 6 (2010) 1669-1678. doi:10.1002/smll.201000528.

[64] M.-L. Rogers, K.S. Smith, D. Matusica, M. Fenech, L. Hoffman, R.A. Rush, et al., Non-viral gene therapy that targets motor neurons in vivo, Front. Mol. Neurosci. 7 (2014) 1-12.

doi:10.3389/fnmol.2014.00080.

[65] D.T. Wiley, P. Webster, A. Gale, M.E. Davis, Transcytosis and brain uptake of transferrin-containing nanoparticles by tuning avidity to transferrin receptor., Proc. Natl. Acad. Sci. U. S. A. 110 (2013) 8662-8667. doi:10.1073/pnas.1307152110.

[66] K.P. García, K. Zarschler, L. Barbaro, J. a. Barreto, W. O’Malley, L. Spiccia, et al., Zwitterioniccoated "stealth" nanoparticles for biomedical applications: Recent advances in countering biomolecular corona formation and uptake by the mononuclear phagocyte system, Small. 10 (2014) 2516-2529. doi:10.1002/smll.201303540. 